\title{
Effects of chemically modified nanostructured PLGA on functioning of lung and breast cancer cells
}

This article was published in the following Dove Press journal:

International Journal of Nanomedicine

15 May 2013

Number of times this article has been viewed

\author{
Lijuan Zhang' \\ Thomas J Webster ${ }^{2}$ \\ 'Department of Chemistry, ${ }^{2}$ School \\ of Engineering, Brown University, \\ Providence, RI, USA
}

Correspondence: Thomas J Webster Department of Chemical Engineering, Northeastern University, 360 Huntington Avenue, Boston, MA 02115, USA

Tel + I 6173736585

Fax + I 6173732209

Email th.webster@neu.edu
Background: The aim of this study was to investigate the effects of poly-lactic-co-glycolic acid (PLGA) nanotopographies with alginate or chitosan protein preadsorption on the functioning of healthy and cancerous lung and breast cells, including adhesion, proliferation, apoptosis, and release of vascular endothelial growth factor (VEGF), which promotes tumor angiogenesis and secretion.

Methods: We used a well established cast-mold technique to create nanoscale surface features on PLGA. Some of the nanomodified PLGA films were then exposed to alginate and chitosan. Surface roughness and the presence of protein was confirmed by atomic force microscopy. Surface energy was quantified by contact angle measurement.

Results: Nanostructured PLGA surfaces with $23 \mathrm{~nm}$ features decreased synthesis of VEGF in both lung and breast cancer cells compared with conventional PLGA. Preadsorbing alginate further decreased cancer cell function, with nanostructured PLGA preadsorbed with alginate achieving the greatest decrease in synthesis of VEGF in both lung and breast cancer cells. In contrast, compared with nonmodified smooth PLGA, healthy cell functions were either not altered (ie, breast) or were enhanced (ie, lung) by use of nanostructured features and alginate or chitosan protein preadsorption.

Conclusion: Using this technique, we developed surface nanometric roughness and modification of surface chemistry that could selectively decrease breast and lung cancer cell functioning without the need for chemotherapeutics. This technique requires further study in a wide range of anticancer and regenerative medicine applications.

Keywords: breast, lung, cancer, nanotechnology, alginate, chitosan

\section{Introduction}

Surface properties, including chemistry, wettability, free energy, and charge, significantly alter cell functioning because they change protein interactions, including adsorption, conformation, and bioactivity, which affects the behavior of cells. ${ }^{1}$ For example, polystyrene films irradiated by an electron beam have been shown to trap charges useful for immobilizing a positively charged protein, ie, avidin-fluorescein, via electrostatic attraction. ${ }^{2}$ Similarly, chitosan-coated nanoparticles with a high degree of deacetylation extend protein conformation because of charge repulsion, allowing such nanoparticles to bind more readily to cell membranes than other conformations of chitosan, such as the coiled conformation, which has less deacetylation. Because of this altered protein conformation, uptake of chitosan nanoparticles by A549 cells increases with increasing deacetylation. ${ }^{3}$ More significantly for the present study, nanometer surface roughness has also been shown to alter local surface energetics, 
which causes significant changes in initial protein adsorption and subsequent cell function.

However, to date, few authors have reported on changes in the surface properties of commonly used tissue regenerative materials that can inhibit the functioning of cancer cells. Poly-lactic-co-glycolic acid (PLGA) is a well known biodegradable polymer in regenerative medicine, and has been proposed as a means of regenerating healthy lung and breast tissue after tumor resection. However, PLGA has no ability to decrease functioning in cancer cells should the disease return. Clearly, it would be advantageous for PLGA to be able to inhibit the recurrence of cancer, so the present study sought to modify the surface of PLGA. Surface features in the nanometer range were created on PLGA using a well established cast-mold process. The surface chemistry of PLGA was also altered using layer-by-layer polyelectrolyte deposition. Specifically, a polyelectrolyte was deposited from an aqueous solution onto the surface containing opposite charges, resulting in reversal of net surface charge. A second oppositely charged polyelectrolyte was further deposited by electrostatic interaction. ${ }^{4} \mathrm{~A}$ pair of biodegradable polyelectrolytes, ie, alginate and chitosan (Figure 1), was used to coat the surfaces of the PLGA for the following reasons: multilayer coatings of alginate and chitosan have antifouling properties resistant to protein adsorption; and multilayers of alginate and chitosan provide many functional groups that can allow covalent attachment of other functional sequences, such as collagen and folic acid, to achieve specific responses by the cells of interest. ${ }^{4,5}$ For example, deposition of bovine serum albumin is not observed on multilayers of alginate or chitosan formed on PLGA nanoparticles when both alginate and chitosan are used as the top layers. ${ }^{5}$ Moreover, uptake of PLGA nanoparticles coated with alginate and

A

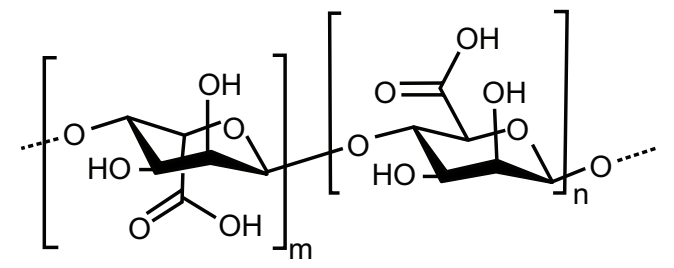

B

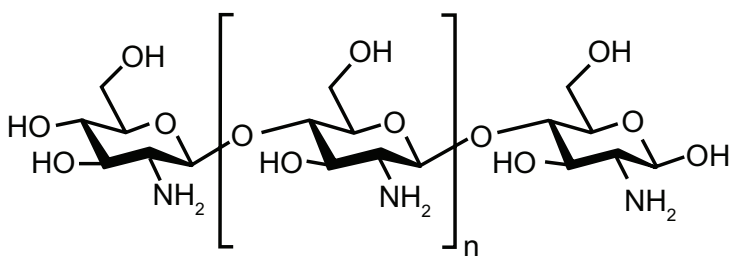

Figure I Chemical formulae for the biological polyelectrolytes used in this study to modify poly-lactic-co-glycolic acid substrates. (A) Alginic acid and (B) chitosan. chitosan by HepG2 cells is significantly less compared with uptake of bare nanoparticles. ${ }^{5}$

The aim of the present in vitro study was to determine the ability of surface features of PLGA in the nanometer range to alter the surface chemistry of breast and lung cancer cells and their functioning. This study provides a mechanism for easy modification of PLGA to decrease the functioning of breast and lung cancer cells selectively without using chemotherapeutic agents which harm healthy cells.

\section{Materials and methods Surface nanometer features and chemical modification of PLGA}

PLGA0 (ie, PLGA with no surface features) and PLGA23 (ie, PLGA with surface features created from $23 \mathrm{~nm}$ diameter polystyrene beads) were prepared using well established cast-mold techniques. ${ }^{15}$ Briefly, polystyrene beads $23 \mathrm{~nm}$ in diameter (Polysciences Inc, Warrington, PA, USA) were placed on glass slides. Following the manufacturer's instructions, polydimethylsiloxane (Sigma-Aldrich, St Louis, MO, USA) was then poured over the glass beads and cured at room temperature for 48 hours to create an inverted mold. PLGA (50:50 wt \% polylactic acid to polyglycolic acid, Polysciences Inc, molecular weight $1 \times 10^{5} \mathrm{kDa}$ ) was then dissolved in chloroform (at a ratio of $0.5 \mathrm{~g}$ per $8 \mathrm{~mL}$ ) and then poured over the mold to create PLGA films with $23 \mathrm{~nm}$ surface features. The same process was followed for PLGA0, except that the soluble PLGA was poured over a flat mold. The PLGA films were then soaked in $70 \%$ ethanol for 20 minutes for sterilization purposes and placed into individual wells of sterile 24-well tissue culture plates. Removal of ethanol from the samples was confirmed by sequential rinses in phosphatebuffered solution and measuring the $\mathrm{pH}$ of the eluant until it reached $\mathrm{pH}$ 7.4. All further treatment steps took place within a biological safety cabinet using sterilized solutions.

Next, for some of the PLGA samples, the chemistry of the PLGA surfaces was altered using a layer-by-layer deposition process, as summarized in Table 1. First, the surfaces were aminolyzed (splitting of functional ester groups by reacting with amine groups) using $1 \mathrm{~mL}$ per well of a $20 \mathrm{mg} / \mathrm{mL}$ solution of polyethylenimine (molecular weight about 2000 Da, Sigma-Aldrich) in water for 60 minutes and rinsing thoroughly with $0.5 \mathrm{M} \mathrm{NaCl}$ three times. This was confirmed by electron spectroscopy for chemical analysis (data not shown). Sodium alginate (Acros Organics, Fair Lawn, NJ, USA) and chitosan (molecular weight about 100-300 kDa, Acros Organics) were assembled separately at concentrations of $1 \mathrm{mg} / \mathrm{mL}$ in $0.5 \mathrm{M} \mathrm{NaCl}$. For solubility, 
Table I Preparation conditions for PLGA surfaces chemically modified by alginate or chitosan

\begin{tabular}{llll}
\hline Name & $\begin{array}{l}\text { Assembly } \\
\text { layers }\end{array}$ & $\begin{array}{l}\text { Layer } \\
\text { composition }\end{array}$ & $\begin{array}{l}\text { Surface } \\
\text { chemistry }\end{array}$ \\
\hline PLGA0 & - & - & PLGA \\
PLGA0/Alg & 2 & PEl/Alg & Alg \\
PLGA0/Chi & 3 & PEI/Alg/Chi & Chi \\
PLGA23 & - & - & PLGA \\
PLGA23/Alg & 2 & PEI/Alg & Alg \\
PLGA23/Chi & 3 & PEI/Alg/Chi & Chi \\
\hline
\end{tabular}

Note: Surface features shown result from the diameter of the particles used. Abbreviations: PLGA0, PLGA surfaces with nanosmooth features; PLGA0/Alg, PLGA surfaces with nanosmooth features and alginate surface chemistry; PLGA0/Chi, PLGA surfaces with nanosmooth features and chitosan surface chemistry; PLGA23, PGLA surfaces with $23 \mathrm{~nm}$ featured nanopatterns; PLGA23/Alg, PLGA surfaces with $23 \mathrm{~nm}$ featured nanopatterns and alginate surface chemistry; PLGA23/Chi, PLGA surfaces with $23 \mathrm{~nm}$ featured nanopatterns and chitosan surface chemistry; PEI, polyethylenimine; Alg, alginate; Chi, chitosan; PLGA, poly-lactic-co-glycolic acid.

the $\mathrm{pH}$ of the alginate and chitosan solutions was adjusted to 5.0 by addition of either $1 \mathrm{M} \mathrm{HCl}$ or $\mathrm{NaOH}$ and sterilized by filtration (pore size $0.22 \mu \mathrm{m}$, Corning Inc, Corning, NY, USA). The alginate solution was then added to the wells ( $1 \mathrm{~mL}$ per well). After 15 minutes, the alginate solution was removed and replaced with $0.5 \mathrm{M} \mathrm{NaCl}$ and rinsed three times, followed by replacement with $1 \mathrm{~mL}$ of the chitosan solution for 15 minutes and rinsing again with $0.5 \mathrm{M} \mathrm{NaCl}$ three times. This process produced PLGA surfaces with different layers of alginate or chitosan.

Confirmation of alginate and chitosan adsorption was determined by adding RPMI buffer (Sigma-Aldrich) to the final materials for 15 minutes and repeating the process three times. The supernatant solutions were then grouped and tested for protein content using the bicinchoninic acid assay (Pierce Biotechnology, Rockford, IL, USA) following the manufacturer's instructions.

\section{Surface characterization}

\section{Atomic force microscopy}

Atomic force microscopic images of all the PLGA films created were obtained in ambient air using an AFM-MFP3D device (Asylum Research, Santa Barbara, CA, USA) and sharp-topped cantilevers with a $\mathrm{K}$ (stiffness) value of $0.06 \mathrm{~N} / \mathrm{M}$. The AFM-MFP3D was operated in contact mode at a scan rate of 256 lines per scan. Root mean square roughness $\left(R_{r m s}\right)$ values of the various substrates were calculated from the scanning data.

\section{Measurement of water contact angles}

Water contact angles on the various PLGA surfaces of interest were measured through the sessile drop shape method under ambient conditions. A drop of deionized water $(3 \mu \mathrm{L})$ was placed on the PLGA surfaces and its profile was recorded immediately using a drop shape analyzer (Easy Drop FM40, Kruss GmbH, Hamburg, Germany). Contact angles were then calculated by computer software (DSA1, Kruss) based on the profile recorded for the water drop. At least five different spots on each sample were measured for statistical purposes $(n=5)$.

\section{Assays in cancerous and healthy lung cells MTT assay of epithelial lung carcinoma cells}

Epithelial lung carcinoma (A549) cells (CCL-185, American Type Culture Collection, Manassas, VA, USA) at population numbers less than seven were used in this study. Cells were cultured under standard conditions. An 3-(4,5-dimethylthiazol2-yl)-2, 5-diphenyltetrazolium (MTT) assay was used to determine cell density. For this, lung carcinoma cells were seeded onto the PLGA surfaces at a density of 50,000 cells $/ \mathrm{cm}^{2}$. After seeding, the cells were cultured in F-12K medium supplemented with $10 \%$ fetal bovine serum (Hyclone, Logan, UT, USA) and $1 \%$ penicillin/streptomycin (Hyclone) under standard cell culture conditions $\left(5 \% \mathrm{CO}_{2}\right.$, humidified air at $37^{\circ} \mathrm{C}$ ). After one day, viable cell numbers were determined using a CellTiter $96^{\circledR}$ nonradioactive cell proliferation assay (G4100, Promega, Madison, WI, USA) that measures reduction (by living cells only) of MTT. One day later, the medium was removed from the wells, and the cells were washed twice with phosphate-buffered solution. All samples were then transferred to fresh 24-well tissue culture plates, and $1 \mathrm{~mL}$ of fresh growth medium was added to each well. Next, $150 \mu \mathrm{L}$ of dye solution from the cell proliferation assay kit was added to each well and the plates were incubated at $37^{\circ} \mathrm{C}$ in a humidified $5 \% \mathrm{CO}_{2}$ atmosphere. After 4 hours, $1 \mathrm{~mL}$ of Solubilization Solution/Stop Mix ${ }^{\circledR}$ (Promega) was added to each well and the plates were allowed to stand overnight in a humidified atmosphere to solubilize the formazan crystals completely. The contents of the wells were then mixed to obtain a uniformly colored solution, and then transferred to 96 -well plates $(215 \mu \mathrm{L}$ per well). Absorbance at $570 \mathrm{~nm}$ was recorded using a microplate reader (Molecular Devices, San Jose, CA, USA). The value of the background absorbance at $570 \mathrm{~nm}$ without cells run in parallel with the experimental samples was subtracted to yield corrected absorbance. The viable cell number was determined from a standard curve of absorbance versus known concentrations of epithelial lung carcinoma cells in solution run in parallel with the MTT assay. All the experiments were performed in triplicate $(n=3)$ and repeated three times $(n=3)$. 


\section{VEGF immunoassay in epithelial lung carcinoma cells}

A quantikine human VEGF immunoassay kit (R\&D Systems, Minneapolis, MN, USA) was used to determine the concentration of vascular endothelial growth factor (VEGF) in cells. The medium for VEGF measurement was collected for the MTT assay after one day of culture, as previously described. The immunoassay was performed according to the manufacturer's instructions. Briefly, $200 \mu \mathrm{L}$ standards (prepared from the kit) and the sample medium were pipetted into the 96-well plate (from the kit) and incubated for 2 hours at room temperature. After washing with binding buffer, an enzyme-linked polyclonal antibody specific for VEGF (from the kit) was added to the wells. Following a wash to remove any unbound antibody-enzyme reagents, a substrate solution (from the kit) was added to the wells and the color developed in proportion to the amount of VEGF bound in the initial step. Color development was stopped and the intensity of the color was measured at $450 \mathrm{~nm}$ using the microplate reader. The VEGF concentration was determined from a standard curve of absorbance versus known concentrations of VEGF run in parallel with the experimental samples. The VEGF assay was conducted in triplicate $(\mathrm{n}=3)$ and was repeated at least three times $(n=3)$.

\section{MTT assay of healthy primary epithelial small airway cells}

Healthy primary epithelial small airway cells (PCS-301-010, ATCC) at population numbers less than five were used. The cells were seeded onto the various PLGA surfaces at a density of $85,000 \mathrm{cells} / \mathrm{cm}^{2}$. After seeding, the cells were cultured in epithelial airway cell basal medium (PCS-300-030, ATCC) supplemented with epithelial small airway cell growth kit components (PCS-301-040, ATCC) under standard cell culture conditions $\left(5 \% \mathrm{CO}_{2}\right.$, humidified air at $\left.37^{\circ} \mathrm{C}\right)$. One day later, the number of viable cells was determined using the CellTiter 96 nonradioactive cell proliferation assay. Viable cell numbers were determined from a standard curve of absorbance versus known concentrations of live epithelial small airway cells run in parallel with the MTT assay as previously described. All experiments were performed in triplicate $(n=3)$ and repeated three times $(n=3)$.

\section{Assays in cancerous and healthy breast cells}

\section{MTT assay in breast epithelial adenocarcinoma cells}

Breast epithelial adenocarcinoma cells (HTB-22, ATCC) at population numbers less than seven were used in this assay. Breast cancer cells were seeded onto the various PLGA surfaces at a density of 50,000 cells $/ \mathrm{cm}^{2}$. After seeding, the cells were cultured in Dulbecco's modified Eagle's medium supplemented with $10 \%$ fetal bovine serum and $1 \%$ penicillin/streptomycin under standard cell culture conditions $\left(5 \% \mathrm{CO}_{2}\right.$, humidified air at $37^{\circ} \mathrm{C}$ ). After one day of culture, viable cell numbers were determined using the CellTiter 96 nonradioactive cell proliferation assay, as previously described. Viable cell numbers were determined from a standard curve of absorbance versus known concentrations of live epithelial breast cancer cells run in parallel with the MTT assay. All the experiments were performed in triplicate $(n=3)$ and repeated three times $(n=3)$.

\section{VEGF immunoassay of epithelial breast adenocarcinoma cells}

The medium for the VEGF measurements was collected after one day of culture using the MTT assay as previously described. The quantikine human VEGF immunoassay kit was used for determining VEGF concentration as mentioned previously. The VEGF assay was conducted in triplicate $(n=3)$ and was repeated at least three times $(n=3)$.

\section{MTT assay of healthy epithelial mammary cells}

Human epithelial mammary cells (HEMpiC, 7610, ScienCell Research Laboratories, Carlsbad, CA, USA) representing healthy epithelial breast cells at population numbers less than five were also used in this study. HEMpiC from ScienCell were isolated from normal human breast tissue. Epithelial mammary cell medium (MEpiCM) consisting of basal medium (ScienCell, 7611), mammary epithelial cell growth supplement (MEpiCGS, ScienCell, 7652) and penicillin/streptomycin (ScienCell, 0503) was used to culture HEMpiC. For the MTT assay, the HEMpiC were seeded on the PLGA surfaces at a density of 35,000 cells $/ \mathrm{cm}^{2}$ and cultured under standard cell culture conditions $\left(5 \% \mathrm{CO}_{2}\right.$, humidified air at $\left.37^{\circ} \mathrm{C}\right)$. After one day, viable cell numbers were determined using the CellTiter 96 nonradioactive cell proliferation assay as previously described. Viable cell numbers were determined from a standard curve of absorbance versus known concentrations in live human epithelial mammary cell solution run in parallel with the MTT assay. All the experiments were performed in triplicate $(n=3)$ and repeated three times $(n=3)$. Of note, different cell seeding densities were used in this study to accommodate specific assays and for obtaining measurable amounts of VEGF.

\section{Statistical analysis}

The results were analyzed using one-way analysis of variance followed by the Student's $t$-test, and the data are expressed as the mean \pm standard deviation. 


\section{Results}

\section{Surface characterization}

\section{Roughness}

As expected, modification of the PLGA surfaces significantly altered their roughness (Figure 2). PLGA23 (PLGA surfaces with $23 \mathrm{~nm}$ surface features) were more rough than the PLGA0 (PLGA without any surface features). After deposition of the monolayers layer-by-layer, the nanosurface pattern of PLGA23 was clearly retained, but a noticeable change in surface roughness of PLGA0, PLGA0/ alginate, and PLGA0/chitosan was seen. The $\mathrm{R}_{\mathrm{rms}}$ results confirmed that there were significant variations in PLGA surface nanotopography (Table 2). Specifically, the surface roughness increased after deposition of the first layer of alginate $\left(\mathrm{R}_{\mathrm{rms}}[\mathrm{PLGA} 0\right.$ /alginate $]>\mathrm{R}_{\mathrm{rms}}[\mathrm{PLGA} 0], \mathrm{R}_{\mathrm{rms}}[\mathrm{PLGA} 23 /$ alginate] $>R_{r m s}$ [PLGA23]), but the $R_{r m s}$ values decreased after further deposition of the chitosan monolayer. It is possible that the addition of another self-assembled monolayer partly filled the space created by the first deposition and so decreased the surface roughness values. These results indicate that layer-by-layer self-assembly changed the surface roughness and, at the same time, changed the surface chemistry. Because the bicinchoninic acid assay results demonstrated no change in the quantity of alginate or chitosan adsorption
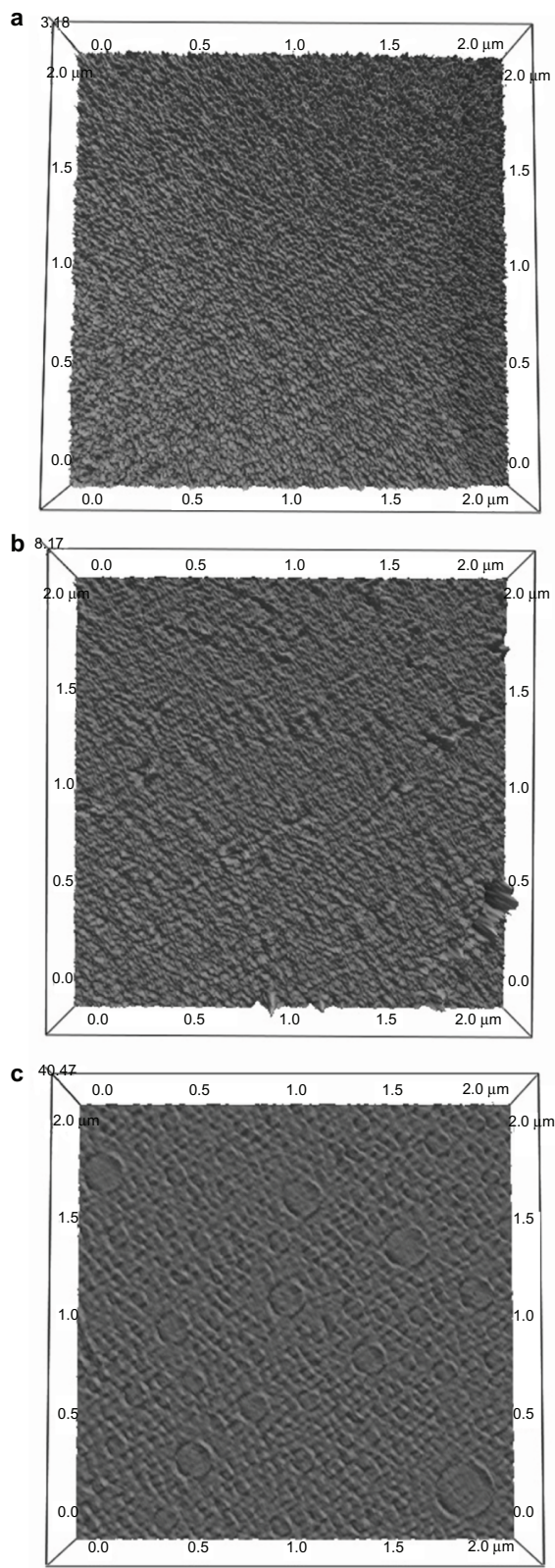

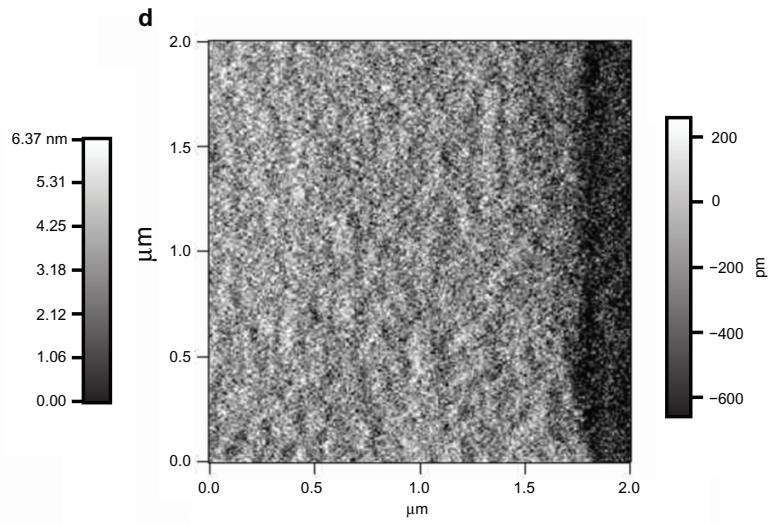

e
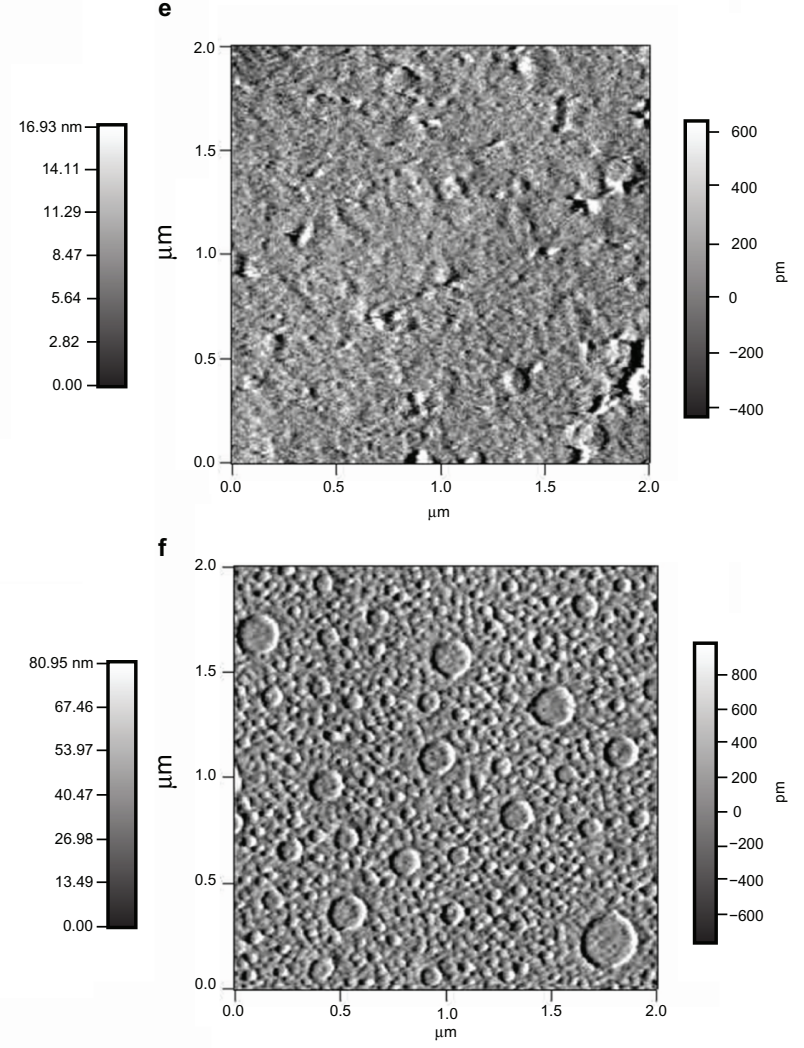

Figure 2 (Continued) 
A

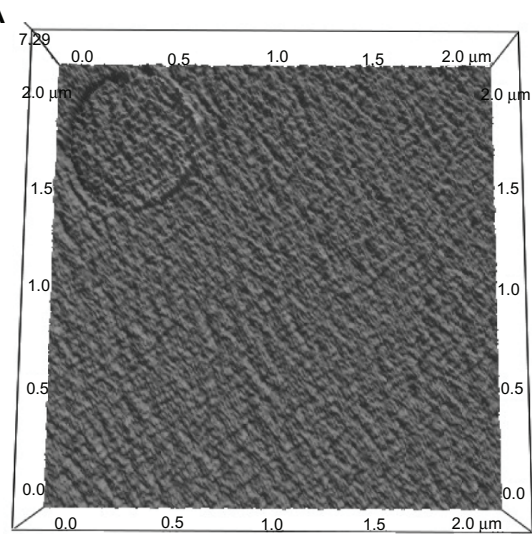

B
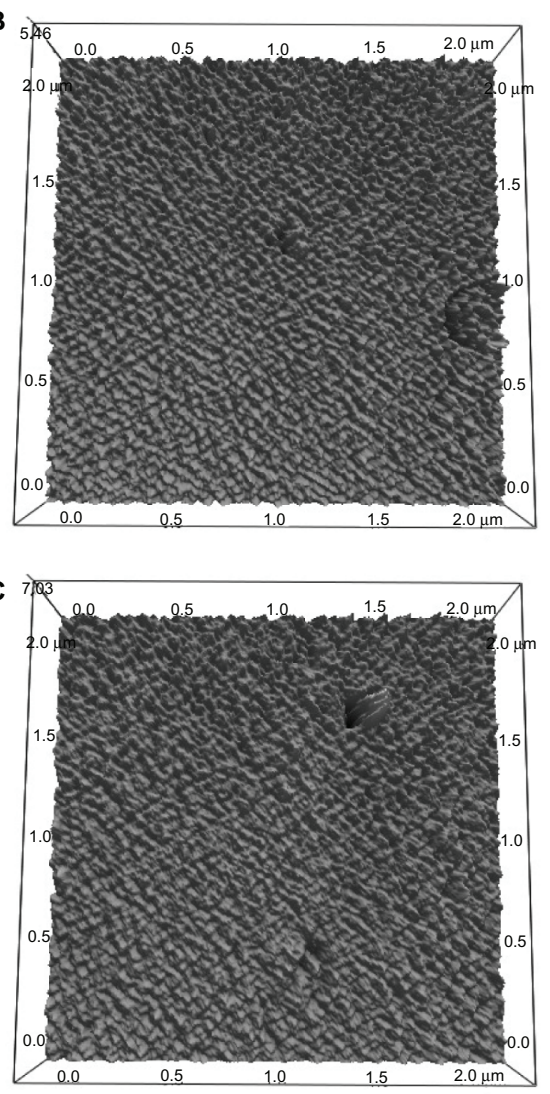

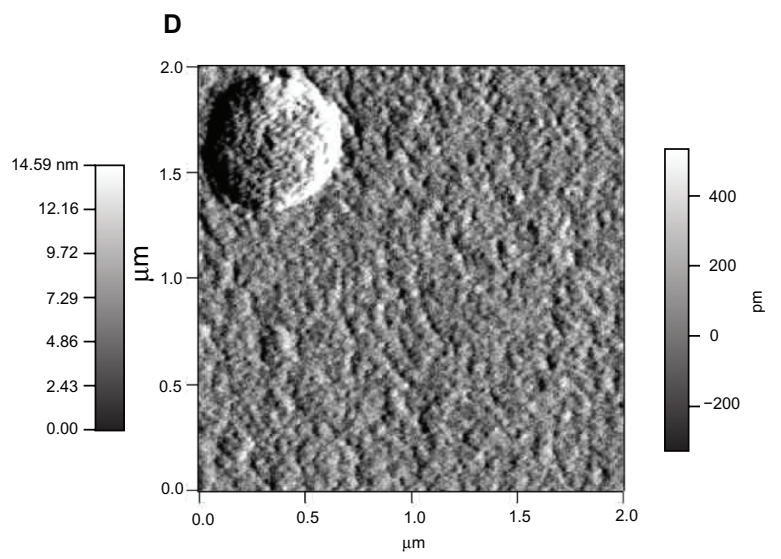

E
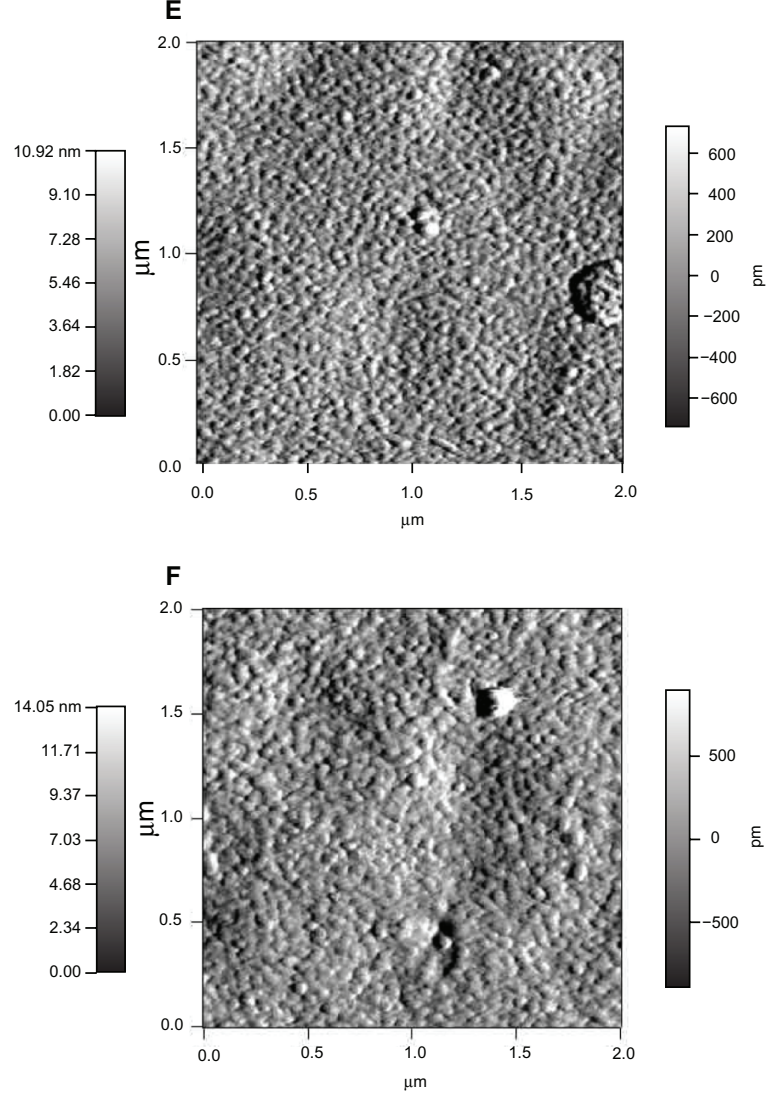

Figure 2 Three-dimensional and two-dimensional atomic force microscopic images of PLGA0 (a and d, respectively), PLGA0/Alg (b and e, respectively), PLGA0/Chi (c and $\mathbf{f}$, respectively), PLGA23 (A and D, respectively), PLGA23/Alg (B and E, respectively), and PLGA23/Chi (C and F, respectively).

Abbreviations: PLGA0, PLGA surfaces with nanosmooth features; PLGA0/Alg, PLGA surfaces with nanosmooth features and alginate surface chemistry; PLGA0/Chi, PLGA surfaces with nanosmooth features and chitosan surface chemistry; PLGA23, PGLA surfaces with $23 \mathrm{~nm}$ featured nanopatterns; PLGA23/Alg, PLGA surfaces with $23 \mathrm{~nm}$ featured nanopatterns and alginate surface chemistry; PLGA23/Chi, PLGA surfaces with $23 \mathrm{~nm}$ featured nanopatterns and chitosan surface chemistry; PLGA, poly-lactic-coglycolic acid; Alg, alginate; Chi, chitosan.

onto the materials of interest (all had $0.55 \mathrm{mg} / \mathrm{cm}^{2}$ of protein adsorption), this change in roughness must be the result of underlying PLGA roughness or altered protein conformation, which needs to be determined in future studies.

\section{Surface wettability}

Water contact angle measurements are shown in Table 2. Surface wettability (ie, hydrophilic or hydrophobic) has been traditionally determined by water contact angles $(\theta)$ according to the definition of hydrophilic surfaces having a water contact angle $(\theta)$ less than $65^{\circ}$. Thus, all the PLGA surfaces in the present study were hydrophobic according to that definition, and chemical modification increased the hydrophilicity of the PLGA surfaces. Water contact angle results indicated the following trend for hydrophobicity: PLGA0 > PLGA0/ alginate > PLGA0/chitosan, and PLGA23 > PLGA23/ 
Table 2 Surface roughness $\left(\mathrm{R}_{\mathrm{rms}}\right)$, local geometric area $\left(\mathrm{S}_{\text {geo }}\right.$, $2 \mu \mathrm{m} \times 2 \mu \mathrm{m})$ and static water contact angles on the various PLGA films

\begin{tabular}{llll}
\hline Substrate & $\begin{array}{l}\mathbf{R}_{\mathbf{r m s}} \\
(\mathbf{n m})\end{array}$ & $\begin{array}{l}\mathbf{S}_{\text {geo }} \\
\left(\mu \mathbf{m}^{2}\right)\end{array}$ & $\begin{array}{l}\text { Contact } \\
\text { angles } \boldsymbol{\theta}\left(\mathbf{H}_{\mathbf{2}} \mathbf{O}\right)\end{array}$ \\
\hline PLGA0 & 0.54 & 4.0 & $98.1 \pm 0.4$ \\
PLGA0/Alg & 5.38 & 4.0 & $80.0 \pm 0.9$ \\
PLGA0/Chi & 3.31 & 4.1 & $87.4 \pm 0.6$ \\
PLGA23 & 3.73 & 4.0 & $93.8 \pm 1.8$ \\
PLGA23/Alg & 7.41 & 4.0 & $76.3 \pm 2.2$ \\
PLGA23/Chi & 5.01 & 4.0 & $68.5 \pm 1.4$ \\
\hline
\end{tabular}

Abbreviations: PLGA0, PLGA surfaces with nanosmooth features; PLGA0/Alg, PLGA surfaces with nanosmooth features and alginate surface chemistry; PLGA0/ Chi, PLGA surfaces with nanosmooth features and chitosan surface chemistry; PLGA23, PGLA surfaces with $23 \mathrm{~nm}$ featured nanopatterns; PLGA23/Alg, PLGA surfaces with $23 \mathrm{~nm}$ featured nanopatterns and alginate surface chemistry; PLGA23/ Chi, PLGA surfaces with $23 \mathrm{~nm}$ featured nanopatterns and chitosan surface chemistry; Alg, alginate; Chi, chitosan; PLGA, poly-lactic-co-glycolic acid.

alginate $>$ PLGA23/chitosan. These results show that the change in surface chemistry had a significant influence on surface wettability as alginate and chitosan made the substrates more hydrophilic. The water contact angle for PLGA0 was higher than that for PLGA23, that for PLGA0/ alginate was higher than that for PLGA23/alginate, and that for PLGA0/chitosan was higher than that for PLGA23/ chitosan. Because PLGA0 and PLGA23 (PLGA0/alginate and PLGA23/alginate, PLGA0/chitosan and PLGA23/ chitosan) had the same surface chemistry, this difference could be attributed solely to altered surface roughness. With the same surface chemistry, increased roughness on nanopatterned surfaces (PLGA23, PLGA23/alginate, and PLGA23/chitosan) demonstrated increased hydrophilicity. The water contact angle of the various PLGA substrates was found to have a strong correlation with both surface chemistry and surface topography.

\section{Responses of cells \\ Proliferation of lung carcinoma cells}

Results for viable epithelial lung carcinoma cells on the various PLGA surfaces after one day in culture are shown in Figure 3. Compared with the pure uncoated PLGA surfaces, the chemically modified surfaces with self-assembled monolayers of either alginate or chitosan significantly increased the numbers of live lung carcinoma cells. Specifically, after one day of culture, the total live lung cancer cell numbers on PLGA0/alginate and PLGA0/chitosan were higher than that on PLGA0 (by $35 \%$ and $30 \%$, respectively). Similarly, PLGA23/alginate and PLGA23/chitosan both showed more live cells than PLGA23 (31\% and 17\%, respectively). However, no significant difference in viable cell numbers was observed between PLGA0/alginate and PLGA0/chitosan or between PLGA23/alginate and PLGA23/chitosan. Moreover, on average, substrates with nanopatterns (ie, PLGA23, PLGA23/alginate, and PLGA23/chitosan) demonstrated significantly greater viable lung cancer cell numbers compared with nanosmooth substrates (ie, PLGA0, PLGA0/alginate, and PLGA0/chitosan).

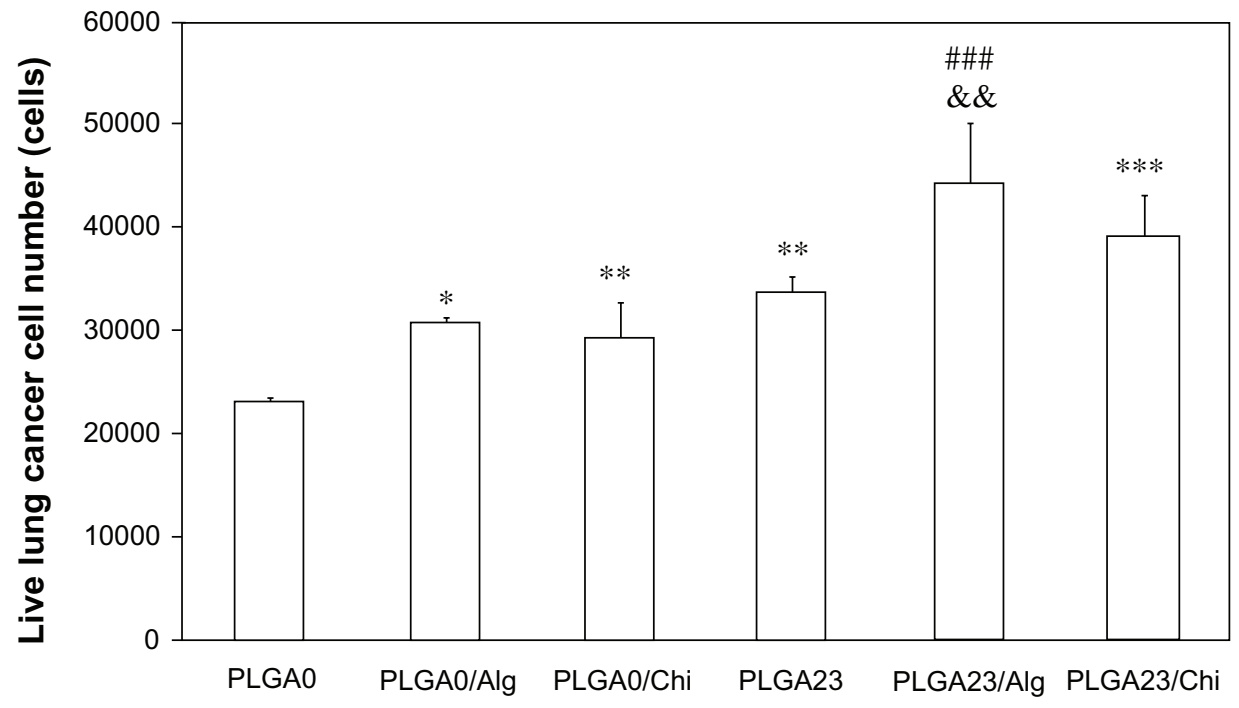

Figure 3 Total live epithelial lung carcinoma cells cultured on the various PLGA substrates for one day.

Notes: Data are expressed as the mean \pm standard error of the mean; $\mathrm{n}=3$. $* P<0.01$ and $* * P<0.05$ versus PLGA0; $* * * P<0.1$ versus $P L G A 0 / C h i$; $P<0.01$ versus PLGA23; ${ }^{2 \& P}<0.05$ versus PLGA0/Alg.

Abbreviations: PLGA0, PLGA surfaces with nanosmooth features; PLGA0/Alg, PLGA surfaces with nanosmooth features and alginate surface chemistry; PLGA0/Chi, PLGA surfaces with nanosmooth features and chitosan surface chemistry; PLGA23, PGLA surfaces with 23 nm featured nanopatterns; PLGA23/Chi, PLGA surfaces with nanosmooth features and chitosan surface chemistry; PLGA23/Alg, PLGA surfaces with $23 \mathrm{~nm}$ featured nanopatterns and alginate surface chemistry; PLGA, poly-lactic-coglycolic acid; Alg, alginate; Chi, chitosan. 


\section{VEGF synthesis by lung carcinoma cells}

Although the chemically modified PLGA surfaces demonstrated more live lung carcinoma cells than the pure uncoated PLGA surfaces, secretion of VEGF by lung carcinoma cells showed impressive contrasting results. VEGF secretion from epithelial lung carcinoma cells after one day in culture on the various substrates is shown in Figure 4. Alginate-modified PLGA surfaces showed a significantly lower concentration of VEGF compared with the unmodified PLGA surfaces. Specifically, cells cultured on PLGA0/alginate secreted on average $12 \%$ less VEGF than did cells cultured on PLGA0. Moreover, cells cultured on PLGA23 secreted 8\% less VEGF than PLGA0, and PLGA23/alginate secreted 10\% less VEGF than PLGA23. Further, cells cultured on PLGA23/ alginate showed $18 \%$ less VEGF secretion compared with those cultured on PLGA0. These results demonstrate that cells cultured on alginate-modified PLGA surfaces secreted less VEGF, regardless of whether they were nanosmooth or $23 \mathrm{~nm}$ nanopatterned.

\section{Responses of healthy epithelial lung cells}

Total live healthy primary epithelial small airway cell numbers after one day in culture are shown in Figure 5. Interestingly, the surface chemistry of PLGA (regardless of whether alginate or chitosan) did not have any statistically significant influence on proliferation of healthy lung cells. There was no significant difference between PLGA0, PLGA0/alginate, and PLGA0/ chitosan. Further, no significant difference was observed between PLGA23, PLGA23/alginate, and PLGA23/chitosan. However, PLGA23 showed, on average, 33\% more viable healthy lung cells than PLGA0. Moreover, PLGA23/alginate and PLGA23/chitosan both showed significantly more viable cells than PLGA0/ alginate or PLGA0/chitosan (37\% and 25\%, respectively). These results indicate that nanotopography plays an important role in the proliferation of healthy epithelial lung cells, whereas the surface chemistry modification of interest in this study had no significant influence.

\section{Proliferation of breast adenocarcinoma cells}

Viable breast adenocarcinoma cell numbers were counted after one day in culture to investigate the effects of surface chemistry and topography. The self-assembled alginate monolayer had a significant influence on the proliferation of these cells (Figure 6). Specifically, PLGA0/alginate had 39\% less viable cells than PLGA0 and $31 \%$ less than PLGA0/chitosan. Similarly, PLGA23/alginate showed significantly smaller live cell numbers compared with PLGA23 and PLGA23/ chitosan ( $31 \%$ and $41 \%$, respectively). However, there was no statistically significant difference between unmodified and chitosan monolayer-modified PLGA surfaces. Further, when comparing various PLGA surfaces with the same chemistry but different surface chemistry, no significant difference was observed between the nanosmooth and nanopatterned PLGA surfaces. However, PLGA0/alginate and PLGA23/alginate both showed significantly lower breast cancer cell numbers compared with any of the other PLGA substrates. Here, breast

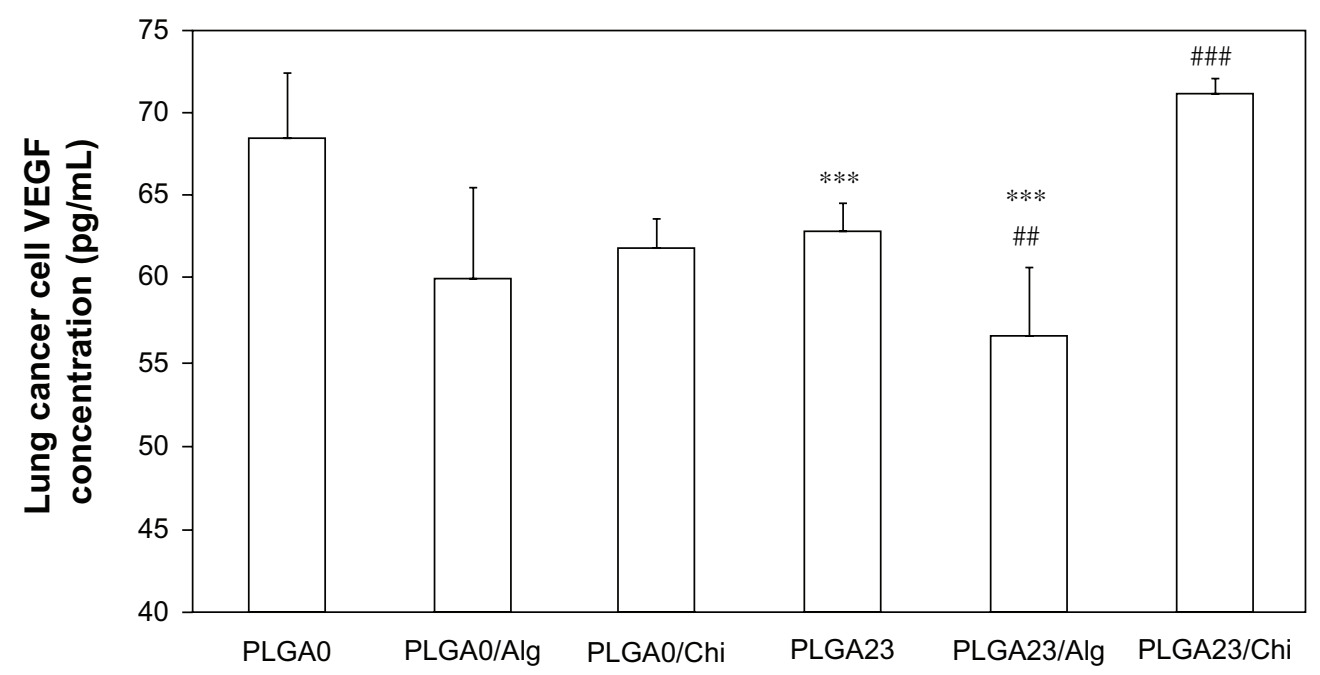

Figure 4 VEGF secretion by lung carcinoma cells cultured on the various PLGA substrates for one day.

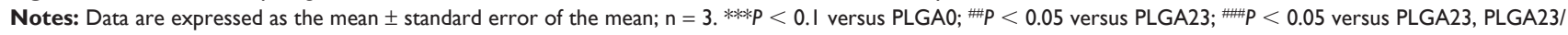
$\mathrm{Alg}$, and PLGA0/Chi.

Abbreviations: PLGA0, PLGA surfaces with nanosmooth features; PLGA0/Alg, PLGA surfaces with nanosmooth features and alginate surface chemistry; PLGA0/Chi, PLGA surfaces with nanosmooth features and chitosan surface chemistry; PLGA23, PGLA surfaces with 23 nm featured nanopatterns; PLGA23/Chi, PLGA surfaces with 23 nm featured nanopatterns and chitosan surface chemistry; PLGA23/Alg, PLGA surfaces with $23 \mathrm{~nm}$ featured nanopatterns and alginate surface chemistry; PLGA, poly-lactic-coglycolic acid; VEGF, vascular endothelial growth factor; Alg, alginate; Chi, chitosan. 


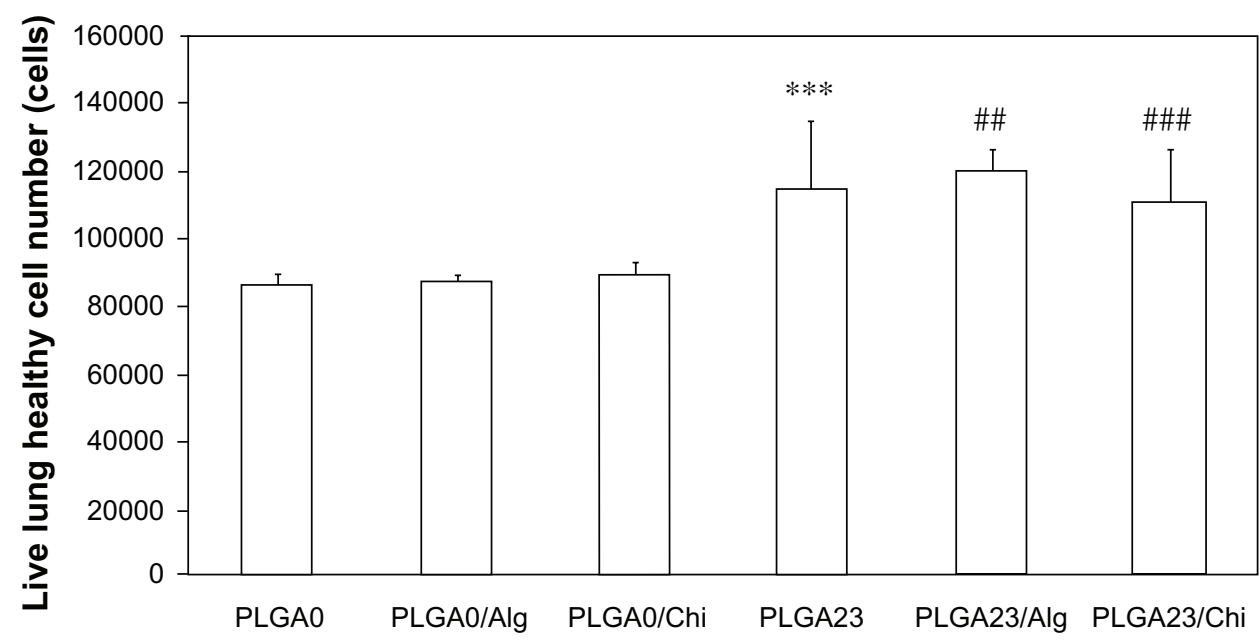

Figure $\mathbf{5}$ Total live cell numbers of healthy primary epithelial small airway lung cells cultured on the various substrates for one day.

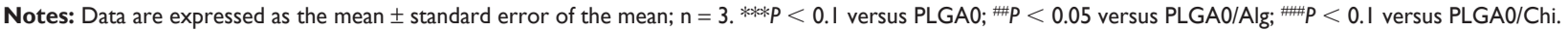

Abbreviations: PLGA0, PLGA surfaces with nanosmooth features; PLGA0/Alg, PLGA surfaces with nanosmooth features and alginate surface chemistry; PLGA0/Chi, PLGA surfaces with nanosmooth features and chitosan surface chemistry; PLGA23, PGLA surfaces with 23 nm featured nanopatterns; PLGA23/Chi, PLGA surfaces with 23 nm featured nanopatterns and chitosan surface chemistry; PLGA23/Alg, PLGA surfaces with $23 \mathrm{~nm}$ featured nanopatterns and alginate surface chemistry; PLGA, poly-lactic-coglycolic acid; Alg, alginate; Chi, chitosan.

cancer cells showed a pronounced dependence on surface chemistry, and alginate showed the strongest inhibition of proliferating breast cancer cells.

\section{VEGF synthesis by breast adenocarcinoma cells}

Total VEGF secreted by breast adenocarcinoma cells after one day in culture on the various chemically modified nanosmooth and nanopatterned PLGA surfaces is shown in Figure 7. Similar to the results for proliferation of breast cancer cells just described, PLGA modified by a self-assembled alginate monolayer decreased secretion of VEGF. Specifically, PLGA0/alginate showed 10\% and 6\% less total VEGF content compared with PLGA0 and PLGA0/chitosan, respectively. Similarly, cells cultured on PLGA23/alginate had significantly lower VEGF concentrations than PLGA23 and PLGA23/chitosan (9\% and 6\% less, respectively). Further, comparing substrates with the same chemistry but different topography, PLGA23, PLGA23/

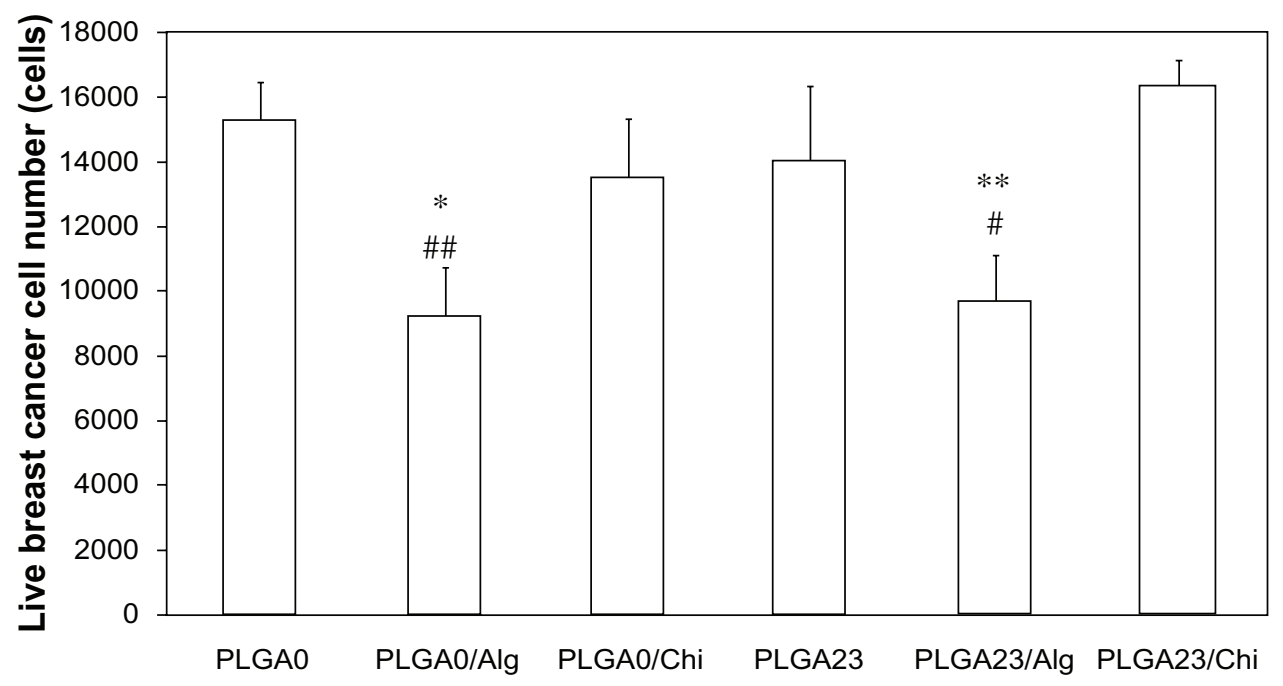

Figure 6 Total live cell numbers of breast epithelial adenocarcinoma cells cultured on the various PLGA substrates for one day.

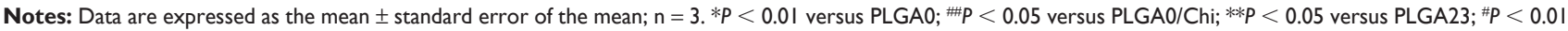
versus PLGA23/Chi.

Abbreviations: PLGA0, PLGA surfaces with nanosmooth features; PLGA0/Alg, PLGA surfaces with nanosmooth features and alginate surface chemistry; PLGA0/Chi, PLGA surfaces with nanosmooth features and chitosan surface chemistry; PLGA23, PGLA surfaces with 23 nm featured nanopatterns; PLGA23/Chi, PLGA surfaces with 23 nm featured nanopatterns and chitosan surface chemistry; PLGA23/Alg, PLGA surfaces with $23 \mathrm{~nm}$ featured nanopatterns and alginate surface chemistry; PLGA, poly-lactic-coglycolic acid; Alg, alginate; Chi, chitosan. 


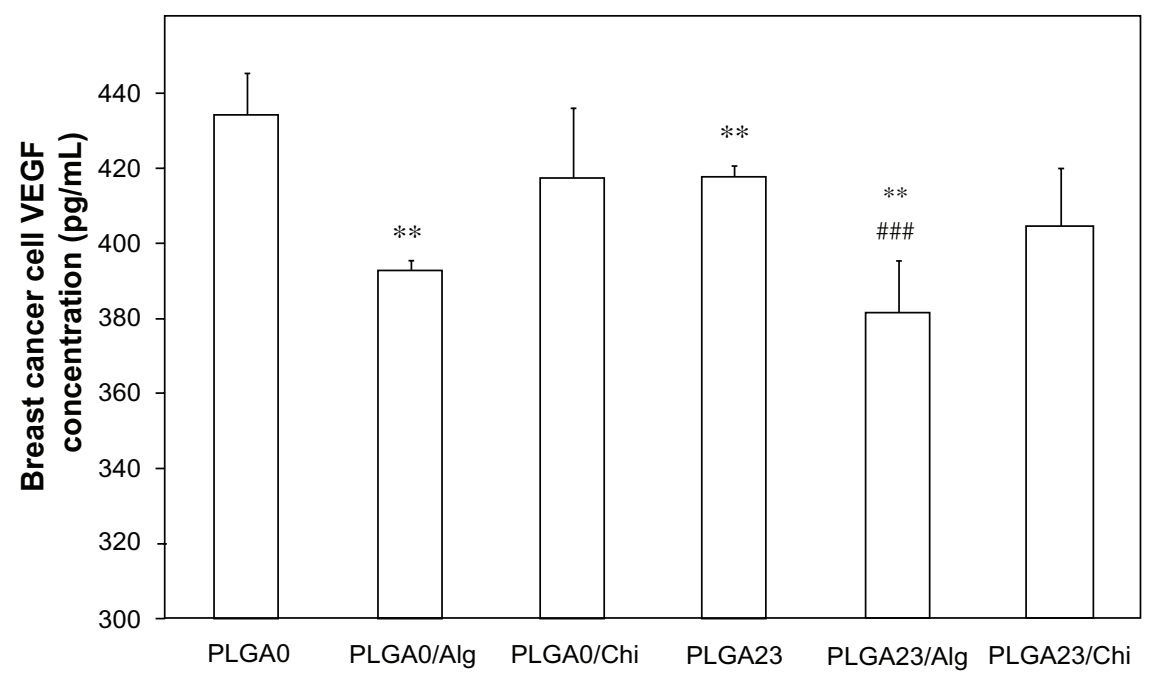

Figure 7 VEGF secreted by breast adenocarcinoma (MCF-7) cells cultured on the various PLGA substrates for one day.

Notes: Data are expressed as the mean \pm standard error of the mean; $\mathrm{n}=3$. $* * P<0.05$ versus $\mathrm{PLGA0}$; $\mathrm{N}<0.01$ versus $\mathrm{PLGA} 23$.

Abbreviations: PLGA0, PLGA surfaces with nanosmooth features; PLGA0/Alg, PLGA surfaces with nanosmooth features and alginate surface chemistry; PLGA0/Chi, PLGA surfaces with nanosmooth features and chitosan surface chemistry; PLGA23, PGLA surfaces with 23 nm featured nanopatterns; PLGA23/Chi, PLGA surfaces with 23 nm featured nanopatterns and chitosan surface chemistry; PLGA23/Alg, PLGA surfaces with $23 \mathrm{~nm}$ featured nanopatterns and alginate surface chemistry; PLGA, poly-lactic-coglycolic acid; VEGF, vascular endothelial growth factor; Alg, alginate; Chi, chitosan.

alginate, and PLGA23/chitosan showed slightly lower average VEGF concentrations than PLGA0, PLGA0/alginate, and PLGA0/chitosan, although these differences were not statistically significant. Although surface chemistry and surface topography both affected VEGF secretion from breast cancer cells, surface chemistry played a more significant role.

\section{Proliferation of healthy breast cells}

It was evident early in this study that PLGA modified by a self-assembled alginate monolayer decreased proliferation of breast adenocarcinoma cells and VEGF secretion. However, for replacement of cancer tissue by healthy tissue, it is also important to investigate the interactions between healthy breast cells and chemically modified nanopatterned PLGA surfaces, so viable HEMpiC numbers were also determined and the results are shown in Figure 8. Comparing the surfaces with the same topography but different surface chemistry, PLGA0/ alginate significantly improved viable healthy breast cell numbers by $15 \%$ compared with PLGA0/chitosan after

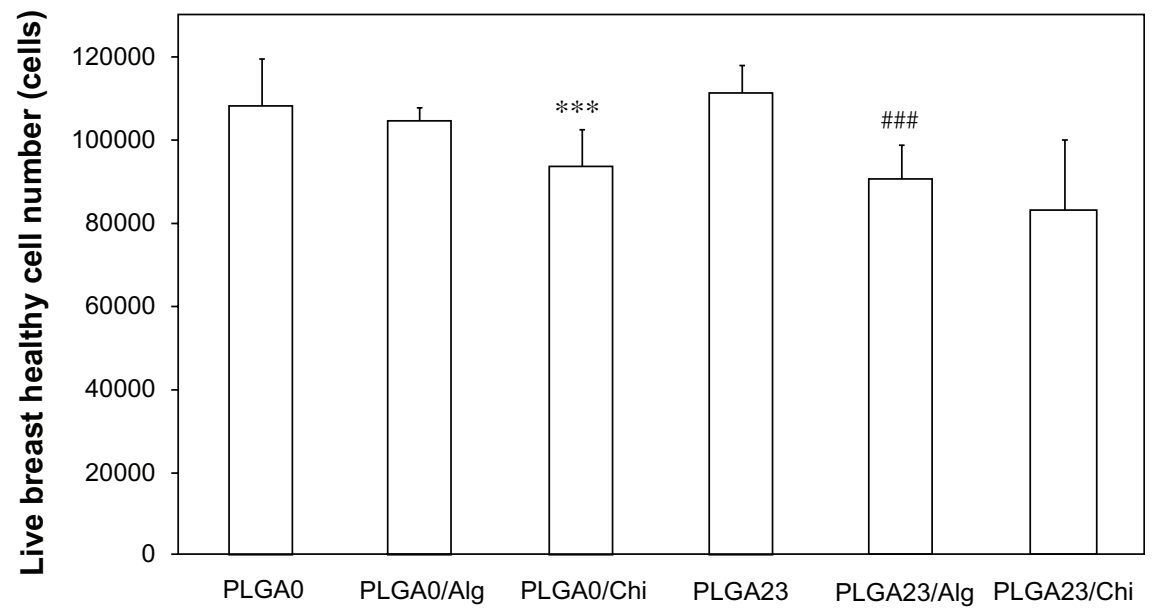

Figure 8 Total live numbers of normal epithelial breast cells cultured on the various PLGA substrates.

Notes: Data are expressed as the mean \pm standard error of the mean; $\mathrm{n}=3$. **** $\mathrm{P}<0.1$ versus PLGA0/Alg; $P<0.1$ versus PLGA23.

Abbreviations: PLGA0, PLGA surfaces with nanosmooth features; PLGA0/Alg, PLGA surfaces with nanosmooth features and alginate surface chemistry; PLGA0/Chi, PLGA surfaces with nanosmooth features and chitosan surface chemistry; PLGA23, PGLA surfaces with 23 nm featured nanopatterns; PLGA23/Chi, PLGA surfaces with 23 nm featured nanopatterns and chitosan surface chemistry; PLGA23/Alg, PLGA surfaces with $23 \mathrm{~nm}$ featured nanopatterns and alginate surface chemistry; PLGA, poly-lactic-coglycolic acid; Alg, alginate; Chi, chitosan. 
one day in culture. However, PLGA23 showed a 22\% increase in viable HEMpiC compared with PLGA23/ alginate after one day in culture. These results confirm that the self-assembled chitosan monolayer decreased proliferation of healthy breast cells and that alginate also slightly decreased their proliferation. In addition, comparing PLGA substrates with the same chemistry but different surface topography, no significant difference was observed between the nanosmooth and nanopatterned substrates. As in breast adenocarcinoma cells, surface chemistry played a more significant role than surface topography in growth of healthy breast cells.

\section{Nominal VEGF per cell for lung and breast cancer cells}

After normalizing the VEGF concentration and total live cell numbers on PLGA0, nominal values for VEGF per cell were obtained on the various substrates (Table 3 ). After one day in culture, lung cancer cells on all the substrates with chemical or nanopattern modifications had lower nominal VEGF per cell values compared with PLGA0. Moreover, lung cancer cells on PLGA23/alginate had the lowest nominal VEGF per cell and had only 0.43 nominal VEGF per cell compared with nanosmooth PLGA. These results indicate that both surface nanometric features and chemical modification decreased the bioactivity of lung cancer cells, especially those cultured on PLGA23/alginate which were significantly less bioactive and secreted much less VEGF than any other substrate used in this study. Importantly, healthy lung cancer cells had a greater density on PLGA23/alginate, demonstrating for the first time selectively increased healthy yet decreased lung cancer cell functions on PLGA with $23 \mathrm{~nm}$ surface features followed by coating in alginate.

A different trend was observed for breast cancer cells, where the least nominal VEGF synthesis was observed on
PLGA23/chitosan, again demonstrating promise for modifying PLGA with $23 \mathrm{~nm}$ surface features followed by coating in chitosan. Importantly, PLGA23/chitosan had no adverse effect on healthy breast cells but brought about a selective decrease in breast cancer cell function.

\section{Discussion}

Layer-by-layer deposition of alginate and chitosan is an easy and versatile technique for chemical modification of a wide range of surfaces. ${ }^{4,8}$ Moreover, alginate and chitosan have been demonstrated to be biocompatible and biodegradable with antifouling properties, so could be ideal candidates for the chemical modification of the surfaces of biomaterials. ${ }^{9,10}$ As shown in this study, layer-by-layer deposition of alginate and chitosan on nanosmooth and nanopatterned PLGA surfaces effectively altered their surface chemistry, wettability, and topography. Deposition of alginate increased surface roughness values on both nanosmooth and nanopatterned PLGA. However, deposition of chitosan produced less rough surfaces. Our results also indicate that layer-by-layer deposition using alginate and chitosan can readily alter the surface wettability of PLGA. Deposition of alginate and chitosan monolayers decreased the hydrophobicity of PLGA, which was expected given that both alginate and chitosan are hydrophilic.

The most important finding of this study was that alginate deposited on PLGA decreased the ability of lung carcinoma cells to secrete VEGF, regardless of whether PLGA is nanosmooth or nanopatterned. Moreover, PLGA23/alginate demonstrated larger decreases in VEGF compared with PLGA0 and both PLGA0/alginate and PLGA23, suggesting surface chemistry and surface nanotopography both had a strong influence on VEGF secretion from lung carcinoma cells. Significantly, for healthy lung cells, after one day in culture, PLGA23, PLGA23/alginate, and PLGA23/chitosan

Table 3 Nominal VEGF per cell on the various substrates after one day in culture

\begin{tabular}{lllllll}
\hline Sample & PLGA0 & PLGA0/Alg & PLGA0/Chi & PLGA23 & PLGA23/Alg & PLGA23/Chi \\
\hline Normalized lung cancer cell VEGF concentration* & 1.00 & 0.88 & 0.91 & 0.92 & 0.83 & 1.04 \\
Normalized total live lung cancer cell number** & 1.00 & 1.35 & 1.30 & 1.48 & 1.94 & 1.74 \\
Nominal VEGF per lung cancer cell*** & 1.00 & 0.65 & 0.70 & 0.62 & 0.43 & 0.60 \\
Normalized breast cancer cell VEGF concentration** & 1.00 & 0.90 & 0.96 & 0.96 & 0.88 & 0.93 \\
Normalized total live breast cancer cell number** & 1.00 & 0.61 & 0.88 & 0.92 & 0.63 & 1.07 \\
Nominal VEGF per breast cancer cell*** & 1.00 & 1.50 & 1.09 & 1.04 & 1.39 & 0.87 \\
\hline
\end{tabular}

Notes: *Normalized VEGF concentration obtained by normalizing all the VEGF concentrations on PLGA0/Alg, PLGA0/Chi, PLGA23, PLGA23/Alg, and PLGA23/Chi to the concentration on PLGA0; **normalized total live cells obtained by normalizing all the total live cell numbers on PLGA0/Alg, PLGA0/Chi, PLGA23, PLGA23/Alg, and PLGA23/ Chi to the total live cell number on PLGA0; ${ }^{* * *}$ nominal VEGF per cell obtained by dividing the normalized VEGF concentration by normalized total live cell number.

Abbreviations: PLGA0, PLGA surfaces with nanosmooth features; PLGA0/Alg, PLGA surfaces with nanosmooth features and alginate surface chemistry; PLGA0/Chi, PLGA surfaces with nanosmooth features and chitosan surface chemistry; PLGA23, PGLA surfaces with 23 nm featured nanopatterns; PLGA23/Alg, PLGA surfaces with $23 \mathrm{~nm}$ featured nanopatterns and alginate surface chemistry; PLGA23/Chi, PLGA surfaces with $23 \mathrm{~nm}$ featured nanopatterns and chitosan surface chemistry; Alg, alginate; Chi, chitosan; VEGF, vascular endothelial growth factor; PLGA, poly-lactic-co-glycolic acid. 
all showed significantly greater viable cell numbers compared with PLGA0, PLGA0/alginate, and PLGA0/chitosan, regardless of surface chemistry. In this study, it was confirmed that nanotopography can have a positive influence on the behavior of healthy lung cells. Future studies will need to delineate the specific cell receptors involved in decreasing the response of lung cancers; this is the likely mechanism for the altered cell responses in the present study because it is known that surfaces with altered surface nanometer roughness and surface energetics promote adsorption of different proteins. It is also known that nanometer surface features in the same size range as proteins can manipulate protein bioactivity, which may also have been the case in the present study and requires further investigation. Data from the present study (specifically, similar alginate and chitosan adsorption on all the samples of interest) suggest that different amounts of alginate and chitosan adsorption (or desorption through cell culture) did not lead to altered cell responses.

Finally, our breast cell studies demonstrate that the alginate-deposited PLGA surfaces, regardless of surface roughness, inhibited proliferation of breast cancer cells, resulting in significantly lower viable cell numbers than pure PLGA and PLGA/chitosan. Alginate has been widely used as a delivery system for anticancer drugs because of its bulk charge, ${ }^{11-13}$ but it has not been reported to have any anticancer activity per se. For example, microcapsules created by deposition of chitosan and alginate onto colloidal particles show a strong ability to accumulate doxorubicin at rates hundreds of times greater than the feeding concentration. ${ }^{12}$ In the present study, negatively charged alginate substrates inhibited VEGF secretion from both lung and breast cancer cells. However, although surface chemistry (especially using alginate) had a significant influence on proliferation of lung cancer cells, effects of surface topography were also detectable.

Importantly, investigation of VEGF secretion by breast cancer cells on various PLGA surfaces showed that alginate could inhibit synthesis of VEGF by these cells. Given that VEGF plays an essential role in tumor development, antiVEGF therapy has been used effectively in the treatment of, for example, metastatic breast cancer. ${ }^{14}$ In the present study, secretion of VEGF by breast cancer cells was effectively inhibited by alginate, especially when surface nanopatterns were present. Both lung and breast cancer cells on PLGA23/ alginate demonstrated lower VEGF concentrations than those on PLGA0/alginate. Therefore, it is reasonable to conclude that the best effect of nanopatterning and surface chemistry was achieved on PLGA23/alginate, and allows for control of PLGA surface properties to achieve specific purposes in directing the functions of cancer cells.

\section{Conclusion}

In this study, layer-by-layer deposition of alginate and chitosan was used to modify the surface chemistry of PLGA, while a cast-mold technique was used to modify its surface roughness. The results indicate that self-assembly layer-bylayer altered the surface chemistry and surface topography of PLGA and decreased its hydrophobicity. Alginate-modified PLGA surfaces had anticancer properties, significantly decreasing VEGF synthesis in lung carcinoma and breast adenocarcinoma cells. Further, alginate-modified PLGA inhibited proliferation of breast adenocarcinoma cells, but had no significant influence on proliferation of lung carcinoma cells. However, studies in healthy breast cells demonstrated a strong correlation with surface topography, with the $23 \mathrm{~nm}$ surface-featured PLGA surfaces promoting proliferation of healthy lung cells, regardless of surface chemistry. These results culminated in identification that PLGA with $23 \mathrm{~nm}$ surface features and coated with alginate would be the best material for regeneration of healthy lung tissue after cancerous tissue has been removed. Similar results were observed for breast cancer cells, in that PLGA with $23 \mathrm{~nm}$ surface features and coated with alginate would be the best material for regeneration of healthy breast tissue after removal of cancerous tissue. More studies are needed to explore further the use of these nanostructured polymers in anticancer and regenerative medicine applications.

\section{Acknowledgment}

The authors would like to thank the Hermann Foundation for funding this research.

\section{Disclosure}

The authors report no conflicts of interest in this work.

\section{References}

1. Lim JY, Donahue HJ. Cell sensing and response to micro- and nanostructured surfaces produced by chemical and topographic patterning. Tissue Eng. 2007;13(8):1879-1891.

2. Wybourne MN, Yan M, Keana JFW, Wu JC. Creation of biomolecule arrays by electrostatic immobilization on electron-beam-irradiated polystyrene thin films. Nanotechnology. 1996;7(3):302-305.

3. Huang M, Khor E, Lim LY. Uptake and cytotoxicity of chitosan molecules and nanoparticles: effects of molecular weight and degree of deacetylation. Pharm Res. 2004;21(2):344-353.

4. Croll TI, O'Connor AJ, Stevens GW, Cooper-White JJ. A blank slate? Layer-by-layer deposition of hyaluronic acid and chitosan onto various surfaces. Biomacromolecules. 2006;7(5):1610-1622. 
5. Zhou J, Romero G, Rojas E, Ma L, Moya S, Gao C. Layer by layer chitosan/alginate coatings on poly(lactide-co-glycolide) nanoparticles for antifouling protection and folic acid binding to achieve selective cell targeting. J Colloid Interface Sci. 2010;345(2):241-247.

6. Meng XN, Jin Y, Yu Y, et al. Characterisation of fibronectin-mediated FAK signalling pathways in lung cancer cell migration and invasion. $\mathrm{Br}$ J Cancer. 2009;101(2):327-334.

7. Zhu X, Zhu L, Duan Z, Qi R, Li Y, Lang Y. Comparative toxicity of several metal oxide nanoparticle aqueous suspensions to Zebrafish (Danio rerio) early developmental stage. J Environ Sci Health A Tox Hazard Subst Environ Eng. 2008;43(3):278-284.

8. Zhou J, Romero G, Rojas E, Ma L, Moya S, Gao C. Layer by layer chitosan/alginate coatings on poly(lactide-co-glycolide) nanoparticles for antifouling protection and folic acid binding to achieve selective cell targeting. J Colloid Interface Sci. 2012;345(2):241-247.

9. Peniche C, Argüelles-Monal W, Peniche N. Chitosan: an attractive biocompatible polymer for microencapsulation. Macromol Biosci. 2003;3(10):511-520.
10. Becker TA, Kipke DR, Brandon T. Calcium alginate gel: a biocompatible and mechanically stable polymer for endovascular embolization. J Biomed Mater Res. 2001;54(1):76-86.

11. Das RK, Kasoju N, Bora U. Encapsulation of curcumin in alginatechitosan-pluronic composite nanoparticles for delivery to cancer cells. Nanomedicine. 2010;6(1):153-160.

12. Zhao Q, Han B, Wang Z, Gao C, Peng C, Shen J. Hollow chitosanalginate multilayer microcapsules as drug delivery vehicle: doxorubicin loading and in vitro and in vivo studies. Nanomedicine. 2007;3(1) 63-74.

13. Arica B, Caliş S, Kaş H, Sargon M, Hincal A. 5-fluorouracil encapsulated alginate beads for the treatment of breast cancer. Int J Pharm. 2002;242(1-2):267-269.

14. Schneider BP, Sledge GW Jr. Anti-VEGF therapy as adjuvant therapy: clouds on the horizon? Breast Cancer Res. 2009;11(3):303.

15. Wang Y, Webster TJ. Increased healthy osteoblast to osteosarcoma density ratios on specific PLGA nanopatterns. Int $J$ Nanomedicine. 2013;8:159-166.
International Journal of Nanomedicine

\section{Publish your work in this journal}

The International Journal of Nanomedicine is an international, peerreviewed journal focusing on the application of nanotechnology in diagnostics, therapeutics, and drug delivery systems throughout the biomedical field. This journal is indexed on PubMed Central, MedLine, CAS, SciSearch $®$, Current Contents $₫ /$ Clinical Medicine,

\section{Dovepress}

Journal Citation Reports/Science Edition, EMBase, Scopus and the Elsevier Bibliographic databases. The manuscript management system is completely online and includes a very quick and fair peer-review system, which is all easy to use. Visit http://www.dovepress.com/ testimonials.php to read real quotes from published authors. 